\title{
Cytoreductive treatment in real life: a chart review analysis on 1440 patients with polycythemia vera
}

\author{
Carl C. Crodel ${ }^{1} \cdot$ Kathleen Jentsch-Ullrich ${ }^{2} \cdot$ Marcel Reiser $^{3} \cdot$ Lutz Jacobasch $^{4} \cdot$ Annette Sauer $^{5} \cdot$ Hans Tesch $^{6}$. \\ Thomas Ulshöfer ${ }^{7} \cdot$ Regine Wunschel $^{8} \cdot$ Francesca Palandri $^{9} \cdot$ Florian H. Heidel $^{1,10}(0)$
}

Received: 28 September 2021 / Accepted: 3 November 2021 / Published online: 22 November 2021

(c) The Author(s) 2021

\begin{abstract}
Purpose Patients with polycythemia vera (PV) show an elevated incidence of thromboembolic complications and decreased survival when compared to age-matched healthy individuals. Hypercellularity as indicated by elevated hematocrit, pathophysiological changes induced by the JAK2 driver mutation and cardiovascular risk factors contribute to the increased incidence of thromboembolic events. Higher age and a history of thromboembolic events define a high-risk population of PV patients. Depending on the individual risk profile, phlebotomy or pharmacologic cytoreduction is recommended in combination with low-dose acetylsalicylic acid. Stringent cytoreduction is required for effective risk reduction. However, in recent reports, the rate of thromboembolic complications in PV patients under cytoreductive therapy appears still elevated compared to healthy individuals. This study reports on a chart review to assess for cytoreductive therapy of $1440 \mathrm{PV}$ patients in real life. Methods Forty-two eligible hematologists/oncologists in private practice treating patients with MPN were recruited to participate in a paper-pencil-based survey conducted between January 2019 and March 2020 in Germany. Physicians were asked to report primary documented data obtained from patient charts. Descriptive analyses were conducted to assess for patient characteristics, treatment modalities, risk factors and thromboembolic complications.

Results Data were collected from the patient charts of 1440 individuals diagnosed with PV. The patient population was older than those reported in multicenter trials with a median age of 72.2 years at the time of reporting and 63.5 years at diagnosis. Age was the main factor accounting for high-risk status with $84.7 \%$ of patients being above the age of 60 followed by thromboembolic complications reported in $21.3 \%$ of patients. The use of pharmacologic cytoreduction was highly variable between participating centers with an average of $60.7 \%$ and a range of 10.1-100\%. Hydroxyurea was the most frequently used drug followed by ruxolitinib, while interferons were reported for a minority of patients. For $35.4 \%$ of patients a persistent need for phlebotomy in addition to cytoreductive treatment was reported. Although presence of high-risk criteria and insufficient disease control were reported as main triggers to initiate pharmacologic cytoreduction, $28.1 \%$ had elevated hematocrit values ( $>45 \%$ ) and $38.6 \%$ showed persistence of elevated leukocyte count $\left(>10^{9 / 1}\right)$ while on cytoreductive treatment. In contrast, physician-reported symptom burden was lower than published in clinical trials and patient-reported outcomes. The rate of patients experiencing thromboembolic complications was 32.2\% at any time and $14.3 \%$ after diagnosis with most patients receiving acetylsalicylic acid and $10.8 \%$ remaining on oral anticoagulants or heparin.

Conclusions Cytoreductive treatment of high-risk PV in real life is highly variable regarding indication for cytoreduction and definition of therapy resistance. This study highlights the need for (i) improved risk stratification for thromboembolic events, (ii) consequent indication of pharmacologic cytoreduction in high-risk PV and (iii) attention to signs of therapy resistance that can trigger an earlier and stringent switch to second line agents.
\end{abstract}

Keywords Polycythemia vera $\cdot \mathrm{PV} \cdot$ Myeloproliferative neoplasia $\cdot$ MPN $\cdot$ Cytoreduction

Florian H. Heidel

florian.heidel@med.uni-greifswald.de

Extended author information available on the last page of the article 


\section{Introduction}

PV is characterized by predominant proliferation of the erythroid lineage, which can be accompanied by hyperplasia of granulopoiesis and megakaryopoiesis. Hyperproliferation of erythroid cells is uncoupled from physiological regulators such as erythropoietin (Epo). The most frequent genetic aberrations in PV are mutations of Janus-kinase 2 (JAK2) (Perner et al. 2019).

Conventional risk stratification in PV is primarily focused on assessing the risk for thromboembolic complications. Nevertheless, the risk for long-term complications, such as leukemia development or myelofibrosis require consideration (Bonicelli et al. 2013; Finazzi and Barbui 2008; Tefferi et al. 2013). Prior history of thrombosis and age are considered the main risk factors for the recurrence of arterial or venous thrombosis (Barbui et al. 2014). More advanced scoring systems include age, history of venous thrombosis and leukocyte counts as established risk factors for survival (Tefferi et al. 2013). The risk for these patients to experience thromboembolic complications is clearly high; however, prognostic parameters beyond age and past medical history of thrombosis are lacking. This leads to challenges in clinical care regarding the indication for and use of cytoreductive drugs and prophylactic treatment with anticoagulants. Most recently, we used a machine learning algorithm to identify risk factors for this high-risk population for clinical use that can predict thromboembolic events (Verstovsek et al. 2019). While prospective validation of these parameters is clearly required, they could be validated in an independent retrospective cohort of PV patients.

First-line treatment for low-risk patients with PV is based on phlebotomies and the use of low-dose ASA, which is a pivotal aspect of PV therapy (Chievitz and Thiede 1962; Lengfelder et al. 2014; Marchioli et al. 2013). In contrast, pharmacologic cytoreduction is recommended for high-risk PV in combination with lowdose ASA therapy (Lengfelder et al. 2014). Cytoreductive drugs should also be considered for low-risk patients who either cannot tolerate phlebotomy, due to high frequency or in case of impending symptomatic iron deficiency. Pharmacologic cytoreduction is also recommended in case of uncontrolled myeloproliferation, characterized by progressive splenomegaly, thrombocytosis or leukocytosis (Barbui et al. 2018; McMullin et al. 2019; Vannucchi et al. 2015a). Cytoreductive agents for clinical use include hydroxyurea (HU) and pegylated interferons (Ropeginterferon-alpha2b) in first line and JAK inhibitors (Ruxolitinib) as a second-line option for HU refractory or intolerant cases.
While multicenter trials investigating therapeutic strategies for PV have been mainly conducted at specialized academic centers, the majority of patients are treated in an outpatient (ambulatory) setting. To assess for the characteristics and treatment modalities in real life we conducted a chart review on cytoreductive treatment modalities.

\section{Patients and methods}

\section{Aims and objectives}

The survey was conducted as a retrospective chart review in primary care centers for patients with hematologic cancers and expertise in the treatment of patients with myeloproliferative neoplasms. Primary goal of this chart review was to assess for frequency, quality and efficacy of cytoreductive therapies in PV patients and for the management of symptoms and complications in this context.

\section{Recruitment of participants}

Recruiting centers have been identified through personal contact and email from a representative panel of boardcertified hematologist-oncologists in Germany. Centers that had successfully contributed to previous chart reviews (Jentsch-Ullrich et al. 2016) were also included. As reported before, physicians had to spend more than $50 \%$ of their time on patient care. In total, 42 centers participated in this evaluation between January 2019 and March 2020. The documentation was terminated prior to the CoVID-19 pandemic and therefore does not contain any CoVID-19-related changes in symptoms, complications or therapeutic measures. The chart review was performed as a paper-pencil-based questionnaire and documentation was compiled in Excel format. Participating centers received financial compensation for their contributions.

\section{Questionnaires}

Identification of MPN patients with the diagnosis of polycythemia vera (PV) according to the WHO classification 2001,2008 or 2016 that were documented in the chart review has been conducted in an unbiased manner through the databases of each participating center. The questionnaire was containing questions on (i) patient characteristics, (ii) past medical history and previous therapies, (iii) current laboratory values and molecular data, (iv) disease-related 
symptoms, (v) current medications and cytoreductive measures and (vi) signs of disease progression.

\section{Diagnosis, response criteria and risk scores}

Diagnosis of PV was confirmed at the participating centers according to the 2001, 2008 or 2016 WHO classifications of myeloid neoplasms (Arber et al. 2016; Barbui et al. 2015b), depending on the date of diagnosis. CTCAE criteria were recommended to report on potential toxicities of cytoreductive measures and the use of ELN criteria were recommended to assess for disease progression (Barosi et al. 2010).

\section{Ethics, consent and permissions}

No identifiable personal information was collected, and the results of the chart review were reported as aggregated datasets of each center. Questionnaires and study materials were reviewed and approved by the institutional review board.

\section{Results}

\section{Patient characteristics}

In total, clinical data on $1440 \mathrm{PV}$ patients were reported by the participating centers. Gender distribution was balanced

Table 1 Patient characteristics

\begin{tabular}{lrc}
\hline Characteristics & $\%$ & Total $n=1440$ \\
\hline Sex & & \\
Male & 45.7 & 658 \\
Female & 54.3 & 782 \\
Age (years) & & \\
$<50$ & 4.2 & 61 \\
$50-59$ & 11.0 & 159 \\
$60-64$ & 8.0 & 115 \\
$65-69$ & 11.5 & 166 \\
$\geq 70$ & 65.2 & 939 \\
Mutation & & \\
JAK2 & 86.9 & 1251 \\
JAK2 negative & 3.3 & 47 \\
N/A & 9.9 & 142 \\
Time since diagnosis (years) & & \\
$<1$ & 2.5 & 36 \\
1-5 & 35.3 & 508 \\
$6-10$ & 29.1 & 419 \\
$>10$ & 32.9 & 474 \\
N/A & 0.2 & 3 \\
\hline
\end{tabular}

with $54.3 \%(n=782)$ female and $45.7 \%(n=658)$ male patients (Table 1). More than half of the patients $(62 \%)$ had been diagnosed more than 5 years prior to the survey, and the majority (97.3\%) had follow-up of more than 1 year after diagnosis. Median age at the time of reporting was 72.2 years and median age at primary diagnosis was 63.5 years. Overall, the patient population was older than in published multicenter trials. $76.7 \%$ of patients were above the age of 65 and $84.7 \%$ of patients above the age of 60 . Thus, age was the main factor accounting for high-risk status.

Thromboembolic complications were reported in 306 patients $(21.3 \%)$ at the time of diagnosis and 206 patients (14.3\%) had thromboembolic complications after diagnosis and during treatment. $69.2 \%$ of patients had no evidence for thromboembolic events. Additional cardiovascular (CV) risk factors were reported by more than two-thirds $(68.1 \%$, $n=981$ ), whereas 432 patients $(30.0 \%)$ had no additional risk factors and in $1.9 \%(n=27)$ of cases no data was reported. Hypertension was the most prevalent CV risk factor with 90.4\% ( $n=887 / 981)$ affected, followed by hypercholesterolemia $18.7 \%(n=183 / 981)$, diabetes mellitus $17.0 \%$ ( $n=167 / 981)$ and smoking $15.4 \%$ ( $n=151 / 981)$ (Fig. 1A, B). This aspect is of major importance as recent studies have highlighted the impact of comorbidities on the outcome of polycythemia vera patients (Benevolo et al. 2021). Taken together, this data indicates a patient population with a high-risk profile (more than $90 \%$ of individuals) regarding thromboembolic complications according to conventional risk stratifications.

\section{Phlebotomy is the primary measure for cytoreduction in PV}

The majority of patients were primarily treated with phlebotomy $(70.3 \%, n=1012$, Fig. 1C). On average, a volume of $250-500 \mathrm{ml}$ blood $(86.1 \%, n=871)$ was drawn and in the majority of cases $(71.2 \%, n=721)$ the same volume of fluid was substituted intravenously. Oral substitution was used by $16.8 \%(n=170)$ of patients. Most patients received less than 1 phlebotomy per month (83.5\%). In more detail, 305 PV patients (30.1\%) received 1-3 phlebotomies/year, 348 (34.4\%) 4-6/year, 197 (19.5\%) 7-12 times/year and 49 patients (4.8\%) received $>13$ phlebotomies/year. For $113(11.25 \%)$ of patients no data for the frequency of phlebotomies was available (Fig. 1D).

Main triggers to proceed to pharmacologic cytoreduction and beyond phlebotomy included the presence of high-risk criteria $(36.8 \%, n=372)$ and insufficient disease control $(41.2 \%$, $n=417)$. Of note, asymptomatic iron deficiency $(4.8 \%, n=49)$, symptomatic iron deficiency $(4.7 \%, n=48)$ and intolerance to phlebotomy $(2.6 \%, n=26)$ have been reported in a relevant number of patients. Also, compliance and patients' decisions contributed to the limitation of phlebotomy treatment. While 
Fig. 1 Cardiovascular risk and phlebotomy treatment. A Percent of PV patients with additional cardiovascular $(\mathrm{CV})$ risk factors $(68.1 \%$, white) In total 1440 patients were analyzed. B Type of cardiovascular risk factor and number of patients for each risk factor out of 981patients with at least one $\mathrm{CV}$ risk factor. $\mathbf{C}$ Percent of $\mathrm{PV}$ patients treated with phlebotomy (70.3\%, white) out of 1440 patients analyzed. D Number of patients undergoing phlebotomy treatment, separated by the number of phlebotomies per year (out of $n=1012 ; 70.3 \%$ )
A

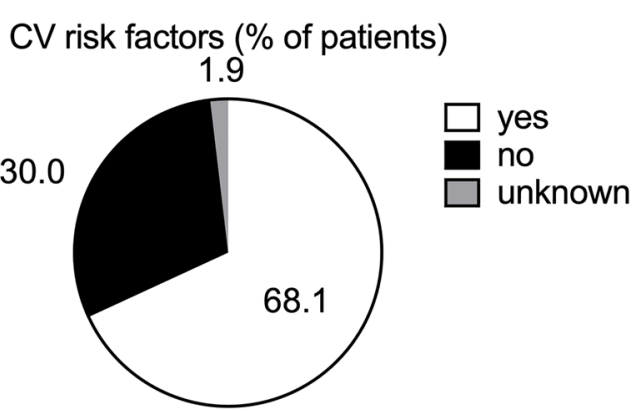

Total $=1440$

B

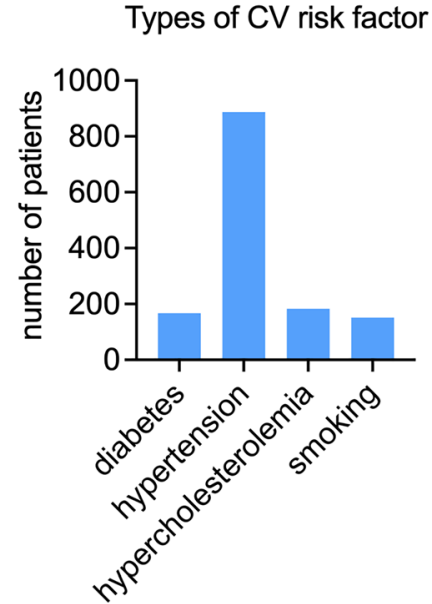

Number of phlebotomies per year

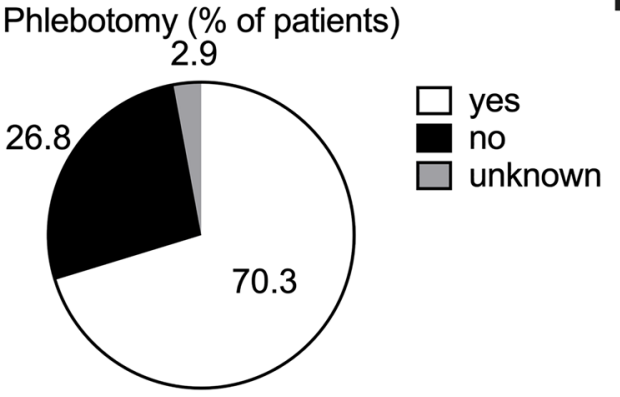

Total $=1440$

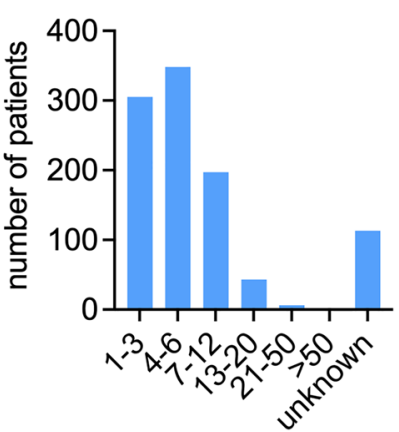

this data highlights the importance of phlebotomy as the primary standard of care, its use should be restricted to avoid secondary complications (Heidel et al. 2018) such as iron deficiency or intolerance which affected more than $10 \%$ of patients in this real-life setting.

\section{Use of pharmacologic cytoreduction in real life is highly variable in a high-risk population of PV patients}

Next, we assessed for the use of pharmacologic cytoreduction in this high-risk patient population. Pharmacologic cytoreduction is indicated for patients with high-risk PV according to current treatment recommendations (Barosi et al. 2013).

Data retrieved from each center was analyzed regarding the total number of PV patients per center (grey bars) compared to those that received pharmacologic cytoreduction (blue bars) (Fig. 2A). Unexpectedly, the fraction of patients treated with pharmacologic cytoreduction was highly variable between the different centers. While the distribution of high-risk patients was comparable between the different investigator sites, the percentage of patients receiving pharmacologic cytoreduction varied between 10.1 and $100 \%$, with an average of $60.7 \%$. When assessing the reasons for lack of pharmacologic cytoreduction in a high-risk patient population among the investigators, patients' objection to pharmacologic treatment due to potential adverse effects was among the main reasons. Moreover, investigators had chosen not to initiate treatment when low-risk patients reached the age-cutoff of 60 years as the main (or sole) cause of being re-categorized as high risk. However, also patients with cardiovascular risk factors and those diagnosed above the age of 60 were among those remaining exclusively on phlebotomy treatment. These findings indicate that in a real-life setting, a relevant number of patients being at high risk for thromboembolic complications ( $>30 \%$ ) do not receive pharmacologic cytoreduction as recommended by current treatment guidelines (Lengfelder et al. 2018; Vannucchi et al. 2015a).

At the date of exploration (01/2019-03/2020) the predominant choices of cytoreductive agents included hydroxycarbamide/hydroxyurea (HU) $(72.3 \%, n=1041)$ and JAK1/2-inhibitor ruxolitinib (RUX) $(22.4 \%, n=323)$ (Fig. 2B). Only a minority of patients received (pegylated) interferons $(2.0 \%, n=29)$, immunomodulatory drugs (IMIDEs) $(0.1 \%, n=2)$ or other cytoreductive agents such as busulfan or anagrelide $(1.4 \%, n=20) .25$ patients $(1.6 \%)$ received combinations of cytoreductive agents. While $\mathrm{HU}$ 
Fig. 2 Frequency and characteristics of pharmacologic cytoreduction. A Total number of patients per center (black) and absolute numbers of patients per center receiving pharmacologic cytoreduction (blue). B Type of pharmacologic cytoreduction, $\%$ of patients. C Number of patients receiving pharmacologic cytoreduction separated by type of treatment and line of therapy. D Percent of patients on phlebotomy treatment while receiving pharmacologic cytoreduction. (E) Percent of patients receiving phlebotomy, separated by the number of phlebotomies per year

$$
\text { A }
$$

B

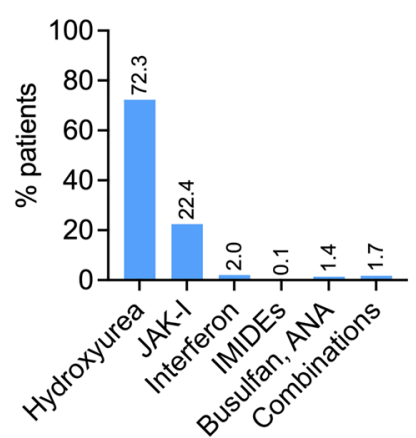

Total number of $P V$ patients

PV patients with pharmacologic cytoreduction

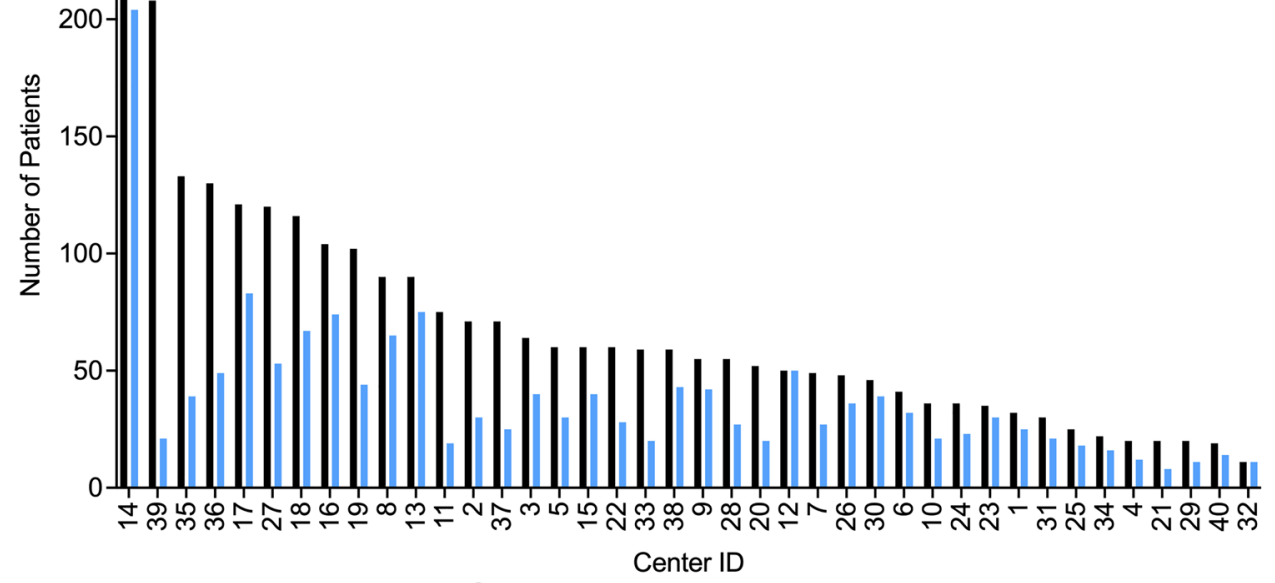

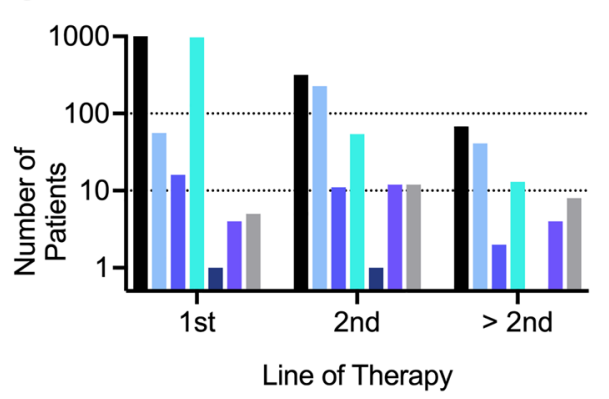

E
C

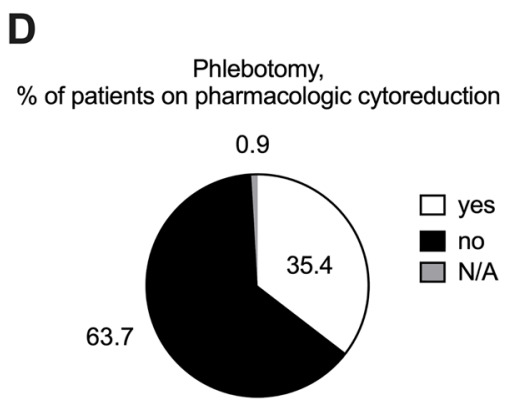

was the most frequent cytoreductive agent used in first-line therapy (Fig. 2C), RUX was the most frequent treatment option for second-line treatment or beyond the second line of treatment. Of note, RUX was also used as first-line treatment in 56 patients while only 16 patients started on pegylated interferon (Fig. 2C).

Of note, for $510(35.4 \%)$ patients a persistent need for phlebotomy within the prior 12 months was indicated (Fig. 2D). Of these, 288 (56.5\%) received 1-3 phlebotomies/year, 165 (32.4\%) 4-6 phlebotomies/year, 37 (7.3\%) $7-12$ phlebotomies/year and 11 patients $(2.2 \%)$ received $>13$ phlebotomies/year, while for $9(1.8 \%)$ frequency was not reported (Fig. 2E). On average $250-500 \mathrm{ml}$ blood $(93.5 \%$, $n=77)$ was drawn and in $83.5 \%$ of cases $(n=426)$ the same volume liquid was substituted intravenously. These findings indicate persistent need for phlebotomies in a significant proportion $(>35 \%)$ of patients receiving pharmacologic cytoreduction. While phlebotomies lower the risk of thromboembolic complications in low-risk PV (Marchioli et al. 2013), persistent need for phlebotomies during pharmacologic cytoreduction indicates insufficient disease control of the drug treatment. Moreover, risk of thrombosis and HU resistance has been linked with the ongoing need of phlebotomies (Alvarez-Larran et al. 2017). Taken together, low rates of pharmacologic cytoreduction in a high-risk PV population and insufficient disease control by pharmacologic cytoreduction may put this population at risk regarding thromboembolic complications. 


\section{Therapeutic efficacy regarding hematologic parameters and symptom burden}

Given the relevant heterogeneity in treatment strategies of this high-risk population as indicated above, we aimed to assess for control of hematologic parameters and diseaseassociated symptoms. Although repeated measurements of individual hematocrit values were not available due to the nature of the chart review, elevated hematocrit values of $>45 \%$ were reported in $28.1 \%$ of patients. While $20.3 \%$ reported with hematocrit values of $45-48 \%, 7.8 \%(n=111)$ patients had values of $49 \%$ or above. These findings indicate that for more than $25 \%$ of PV patients on pharmacologic cytoreduction, insufficient control of hematocrit values could be documented. To assess for a second parameter regarding disease control, we analyzed leukocyte counts documented for this patient population. Leukocyte counts are frequently elevated in PV patients and have been verified as a relevant parameter for PV risk stratification (Tefferi et al. 2013). Moreover, several studies have identified an association between leukocytosis and an increased risk of thromboembolic events in patients with PV (Barbui et al. 2015a; De Stefano et al. 2010; Gangat et al. 2007; Lim et al. 2015). In this analysis, $38.6 \%(n=556)$ patients showed white blood counts (WBC) of $10^{9 / 1}$ or more, while $16.7 \%(n=241)$ had an elevated $\mathrm{WBC}$ of $15^{9 / 1}$ or above upon cytoreductive measures. Persistent leukocytosis despite cytoreductive measures is an indicator of insufficient disease control. In line with the variable number of high-risk PV patients on pharmacologic cytoreduction and the persistent need for phlebotomies in a relevant number of patients, these data indicate lack of stringent cytoreduction according to current treatment recommendations (Barosi et al. 2013).

Beyond the control of hematologic parameters which are indicators for thromboembolic risk, symptom control represents another important therapeutic goal. PV patients suffer from debilitating symptoms irrespective of their risk stratification and therapy, leading to reduced productivity and quality of life (Harrison et al. 2017; Mesa et al. 2016). In this study, classical constitutional symptoms (fever, weight loss, night sweats), general MPN-associated symptoms (fatigue, early satiety, abdominal discomfort, inactivity, problems with concentration, itching, joint/bone pain), splenomegaly and symptoms associated with thrombosis and bleeding were assessed. Moreover, consequences of these symptoms regarding inability to work and reduced working hours were assessed during chart review. Constitutional symptoms were reported in less than $5.5 \%$ of patients for all three parameters. While fatigue $(20.5 \%)$, problems with concentration (20.1\%) and inactivity (18.3\%) were the most frequently reported general symptoms, the overall symptom burden was modest compared to symptoms reported in published clinical trials. While $8.2 \%$ of patients reported microcirculatory symptoms, $4.1 \%$ and $3.2 \%$ reported on bleeding and signs of thrombosis, respectively. While palpable splenomegaly could be documented in $16.3 \%$ of this high-risk PV population, $36.8 \%$ of patients could be diagnosed with splenomegaly by sonographic control. Overall, the symptom burden appeared to be moderate compared to symptoms published in previous trials (Vannucchi et al. 2015b) or patientreported questionnaires (Harrison et al. 2017; Mesa et al. 2016). Consistently, reduced working hours and inability to work were reported at low numbers with $4.8 \%$ and $1.5 \%$, respectively. Of note, discrepancies between physician- and patient-reported symptoms have been reported previously.

\section{Thromboembolic complications}

Thromboembolic complications (TEC) represent a major clinical challenge in treatment of PV patients. Patients with high-risk PV show an annual risk for thromboembolic complications of $3.14 \%$ compared to $2.23 \%$ in low-risk PV, $0.9 \%$ in individuals with cardiovascular $(\mathrm{CV})$ risk factors and $0.6 \%$ in individuals without CV risk (Alvarez-Larran et al. 2012; Tefferi et al. 2013). Recently published data analyzing risk of thromboembolic events in MPN patients reported that at an early timepoint after diagnosis ( 3 months) PV patients showed 3- and 13-fold higher risk of arterial and venous thrombosis, respectively, compared with age- and gendermatched controls (Hultcrantz et al. 2018). In previous studies, thromboembolic events have been reported in 12-27\% of PV patients and those events were frequently reported in the time before diagnosis or at diagnosis (Polycythemia vera: the natural history of 1213 patients followed for 20 years. Gruppo Italiano Studio Policitemia 1995; Barbui et al. 2014; Cerquozzi et al. 2017; Grunwald et al. 2018; Marchioli et al. 2013).

In our chart review analysis, $32.2 \%$ of patients experienced thromboembolic events or major bleeding at any time (before or after diagnosis) and irrespective of concomitant therapy (Fig. 4A). This higher rate of thromboembolic complications can be explained by the high-risk category of PV patients investigated in this analysis. Unfortunately, thromboembolic complications were not stratified by the type of event (arterial versus venous thromboembolism). Consistent with previous reports, the majority of thromboembolic events were reported before diagnosis with $21.3 \%$ of patients (Fig. 4B). 14.3\% of patients experienced thromboembolic complications after diagnosis (Fig. 4C).

Besides cytoreductive therapy, patients with PV are treated with antiplatelet agents and those with a history of thromboembolic complications are treated with anticoagulants such as oral anticoagulants (OAC, NOAC) or heparins (Griesshammer et al. 2019). Combination of cytoreduction and antiplatelet/anticoagulant therapy has shown an advantageous benefit-risk profile (De Stefano et al. 2018). 
Regarding antiplatelet therapy, we found $61 \%$ of patients receiving documented treatment with acetylsalicylic acid and $2.2 \%$ of patients receiving $\mathrm{P} 2 \mathrm{Y} 12$ antagonists (e.g. clopidogrel) (Fig. 4D). A total of $10.8 \%$ of patients were treated with anticoagulants, such as OACs $(4.8 \%)$, NOACs (5.7\%) and low molecular weight heparins (LMWH, 0.3\%). Combinations of antiplatelet agents and anticoagulants were reported in $1.8 \%$ of cases. Notably, lack of data was documented in $24.1 \%$ of cases (Fig. 4D), which can be explained by the fact that a relevant proportion of patients purchase acetylsalicylic acid products without prescription of their physician. The use of acetylsalicylic acid could be confirmed for the majority of these patients during data discussion among the contributing centers, while a small proportion of patients did not receive antiplatelet therapy due to the use of anagrelide (Fig. 2B). Taking this into consideration, the use of antiplatelet agents was comparable to recently published studies (De Stefano et al. 2018). In contrast, the use of anticoagulants in only $10.8 \%$ of patients within a high-risk PV population with $32.2 \%$ of patients having experienced thromboembolic complications raised questions about the duration and termination of anticoagulant treatment. While this chart review did not assess for treatment duration and reasons for discontinuation, this data indicates time-restricted use of anticoagulants according to treatment recommendations for non-cancer patients and switch to continued antiplatelet therapy thereafter.

\section{Discussion}

Thromboembolic complications (TEC) are the most prevalent clinical challenge in patients with PV (Alvarez-Larran et al. 2017; Griesshammer et al. 2019). Up to $40 \%$ of PV patients experience thromboembolic events with arterial and venous thromboses as major determinants of morbidity and mortality. Patients with PV show an annual risk for thromboembolic complications of $3.14 \%$ and $2.23 \%$ for high-risk and low-risk PV, respectively (Alvarez-Larran et al. 2012; Tefferi et al. 2013). Regarding lethal complications of thromboembolic events in patients with PV an annual rate of 1.1-4.4\% was reported (Marchioli et al. 2013; Tefferi 2013). The main therapeutic strategy in patients with PV is risk reduction regarding thromboembolic complications by controlling haematocrit (HCT) to $<45 \%$ in combination with antiplatelet therapy. Both measures have led to reduced rates of thromboembolic complications and death (Finazzi et al. 2005; Marchioli et al. 2013). So far, low-risk status is defined by age $<60$ years and lack of prior thromboembolic complications. Phlebotomy as a prophylactic measure of risk reduction should result in a rather mild iron deficiency to achieve a state of iron-deficient erythropoiesis and hematocrit control without inducing severe iron-deficiency syndrome. The majority of patients may eventually experience reduction of phlebotomy frequency over time and phlebotomy will be sufficient for hematocrit control without pharmacologic intervention. Progressive splenomegaly, leukocytosis, thrombocytosis, disease-associated symptoms or persistent or high need of phlebotomies may also indicate the need for pharmacologic cytoreduction in low-risk PV patients (Barbui et al. 2011). High-risk patients as defined by age $\geq 60$ years and/ or with a history of thromboembolic complications (TEC) should be treated with pharmacologic agents for cytoreduction as first-line treatment (Barbui et al. 2018). In this chart review the patient population was of older age compared to published clinical trials (Vannucchi et al. 2015b) and similar to published real life data (Jentsch-Ullrich et al. 2016; Parasuraman et al. 2015). While age was the main factor accounting for high-risk status followed by thromboembolic complications, the vast majority of patients $(>85 \%)$ could be categorized as high risk. Unexpectedly and in contrast to published datasets (Benevolo et al. 2021) the indication and use of pharmacologic cytoreduction was highly variable in this chart review. While at least $85 \%$ of patients had a clear indication for pharmacologic cytoreduction at the time of analysis, only $60.7 \%$ received cytoreductive medication, with a high inter-center variability (10.1-100\%). These findings were discussed with investigators from participating center to understand the low number of high-risk patients receiving cytoreductive medication. Among the main reasons for declining pharmacologic cytoreduction, patients' and physicians' objection to pharmacologic treatment due to potential adverse effects were reported, especially regarding the use of hydroxyurea and interferons. In Germany, oral hydroxyurea (HU) or subcutaneous, bi-weekly ropeginterferon are the recommended first-line agents, while JAK-inhibitor ruxolitinib is available as a second line option following $\mathrm{HU}$ (Lengfelder et al. 2018). However, according to the investigators, the use of ropeginterferon was restricted to a low number of patients due to concerns about price and potential side effects. Moreover, when patients were diagnosed below the age of 60 reached the "age-cutoff" of 60 , age was not accepted as a sole trigger to initiate pharmacologic cytoreduction, even in the presence of other cardiovascular risk factors. These findings highlight the need for improved risk stratification using novel biomarkers (Verstovsek et al. 2019) and also to emphasize the proven benefit of pharmacologic cytoreduction. Previous studies had already shown a significant advantage for HU compared to phlebotomy regarding the incidence of cardiovascular events (3.0 versus 5.8/100 person-years, $p=0.002$ ) (Barbui et al. 2017). Despite therapy, PV patients on HU still have a significant thrombotic risk (Alvarez-Larran et al. 2016), which can be explained by poorly controlled HCT and persistent need of phlebotomies (Alvarez-Larran et al. 2017), as described in our analysis above (Figs. 1C-D, and 3A-B). Use of HU 

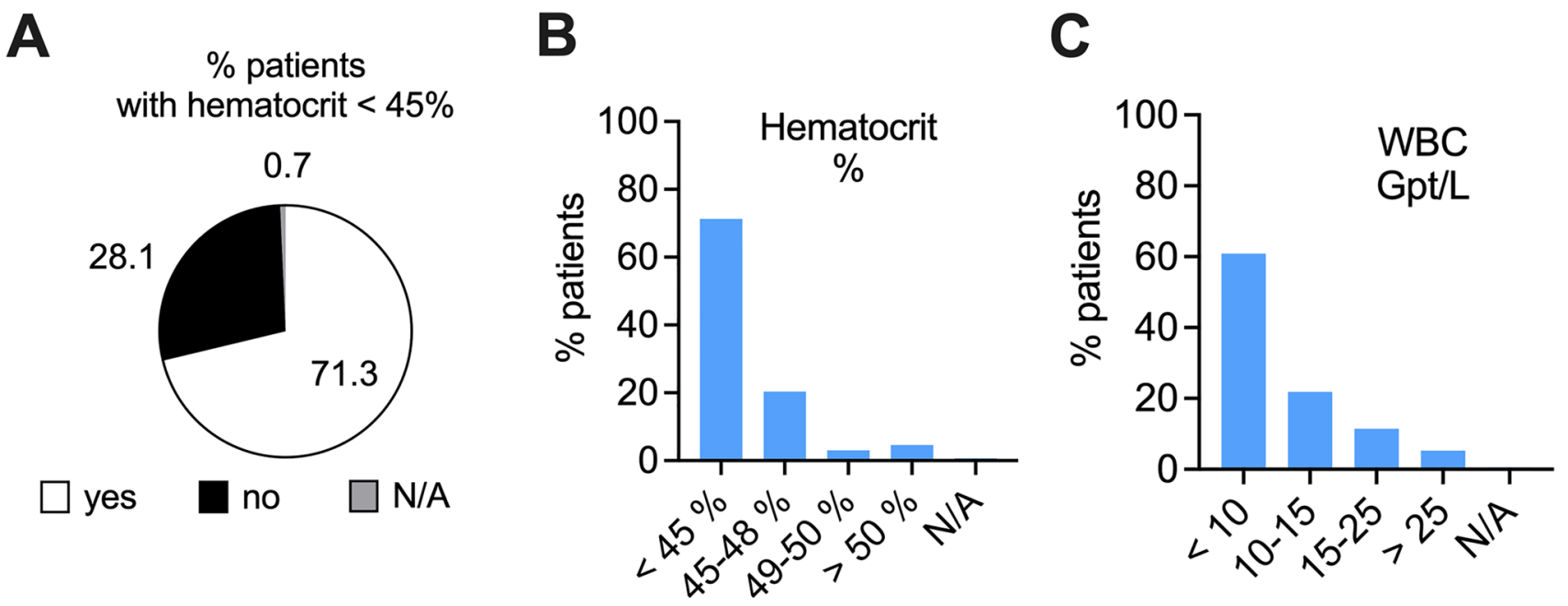

D

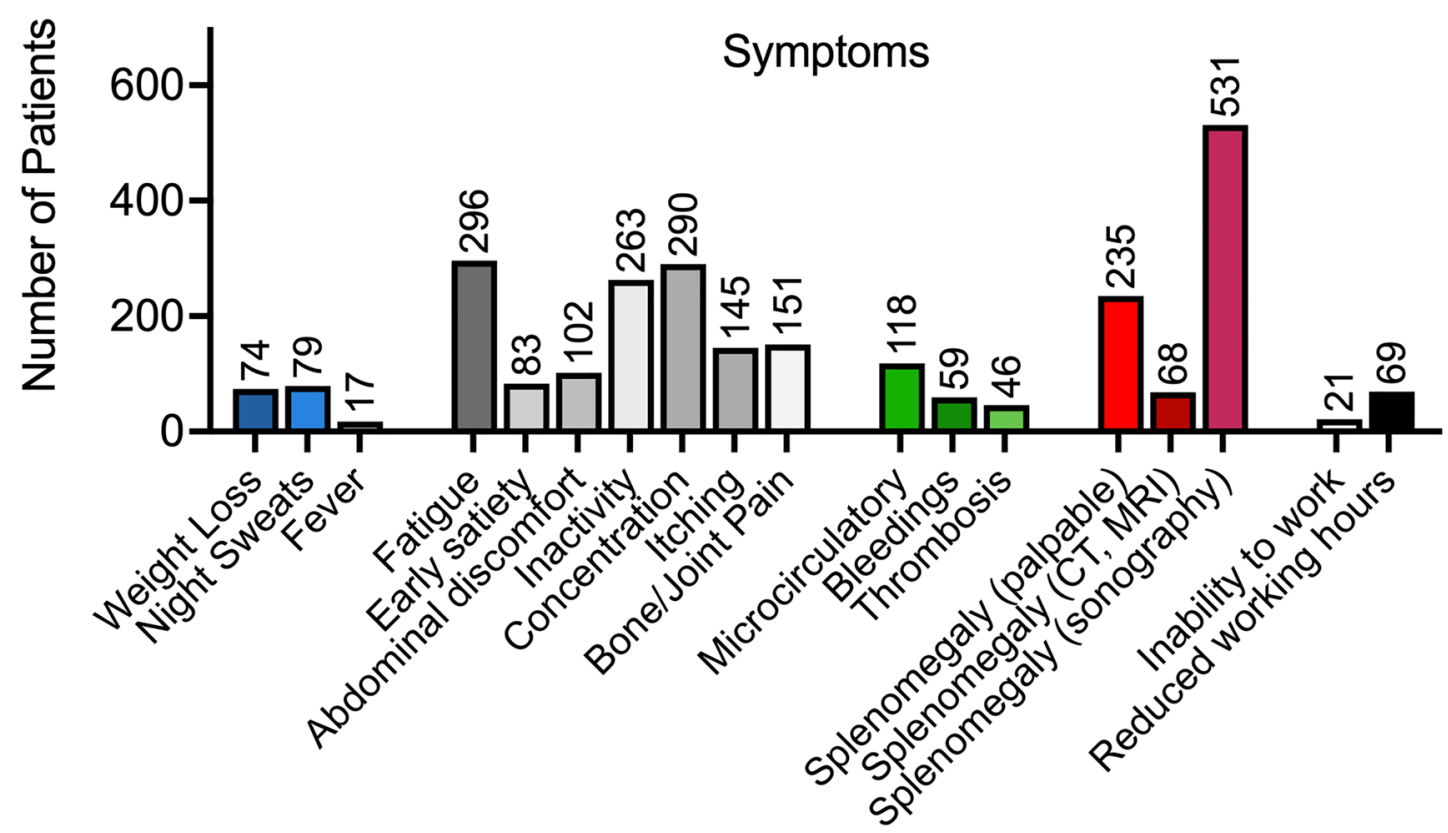

Fig. 3 Hematologic parameters and disease-associated symptoms upon cytoreductive treatment. A Fraction of patients that achieve hematocrit (Hct) levels below 45\%. B Fraction of patients separated by hematocrit levels (in \%). C Fraction of patients separated by leukocyte (WBC) numbers (in Gpt/L). D Number of patients that reported constitutional symptoms (blue), general disease-associated symptoms (grey), bleeding or thrombosis (green), splenomegaly (red) and working capability (black) during cytoreductive treatment

JAK2-V617F allelic burden, and reducing rates of thrombosis, while discontinuation occurs in a relatively low number of patients (approx. 25\%) when compared to early interferon trials (Kiladjian et al. 2006, 2008), HU treatment (Griesshammer et al. 2019) or even ruxolitinib therapy in other subtypes of MPN (Palandri et al. 2020). In our study, the frequent use of ruxolitinib as a second-line option (Fig. 2C) indicates the relevant need to switch from hydroxyurea due to toxicities or insufficient disease and symptom control. 


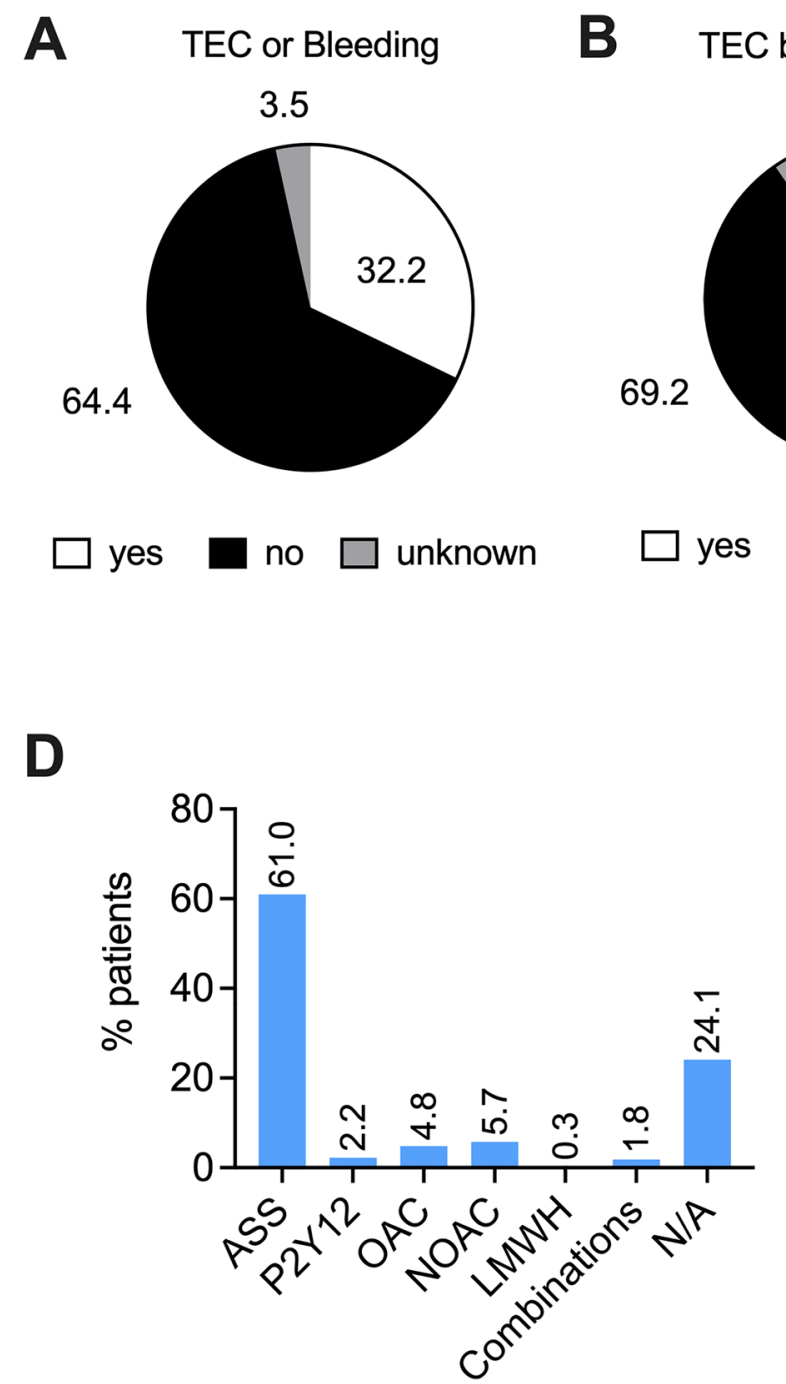

Fig. 4 Occurrence of thromboembolic complications (TEC) or severe bleeding events and concomitant use of anticoagulants. A Fraction of patients experiencing TEC or bleeding at any time. B Fraction of patients with TECs before PV diagnosis (as assessed from past medi-

Reduced quality of life due to debilitating symptoms, including pruritus, fatigue and bone pain has been described in recent studies (Harrison et al. 2017; Mesa et al. 2016). According to these studies, disease-associated symptoms impact on the patients' health, activity and productivity as indicated by reduced working hours in $37 \%$ of PV patients and inability to work in $15 \%$ (Mesa et al. 2016). In contrast, only $4.8 \%$ and $1.5 \%$ of patients were reported with reduced working hours and inability to work, respectively, in our physician-reported chart review. This relevant discrepancy can be explained by differences in treatment goals and perception of symptom burden between MPN patients and physicians (Jentsch-Ullrich et al. 2016; Mesa et al. 2017). On the other hand, part of this effect may also be explained in part by the frequent use of ruxolitinib as a second line (>20\%) cal history). C Fraction of patients with TECs after diagnosis and initiation of PV therapy. D Use of anticoagulants indicated as \% of patients using either compound

(or even first line) agent. Ruxolitinib has been shown to be superior to PV standard therapy in controlling hematocrit, reducing spleen size, and improving symptoms associated with polycythemia vera in patients with HU failure (Vannucchi et al. 2015b) and can therefore be considered an effective second line option. Its use may be limited in patients experiencing recurrent infections (Crodel et al. 2020; Landtblom et al. 2020; Polverelli et al. 2015).

Previous studies have shown that use of acetylsalicylic acid prevented thromboembolic complications (TEC) in PV patients (Landolfi et al. 2004). Use of low-dose acetylsalicylic acid reduced the risk of major thromboembolic complications and death from cardiovascular events (HR 0.40 [95\% CI 0.18-0.91] and a $p$-value of 0.03). As reported in this chart review, the majority of patients were either treated with 
low-dose acetylsalicylic acid (ASS, $100 \mathrm{mg}$ per day) per prescription $(61 \%$, Fig. 4D) or by purchasing the drug without prescription (24.1\%). In contrast, the low fraction of patients receiving anticoagulants (10.8\%) was surprising, given an overall rate of patients with thromboembolic complications of $32.2 \%$ (Fig. 4). Of note most patients experienced TECs prior to diagnosis $(21.3 \%)$, which is in line with published results. $14.3 \%$ of patients, however, reported thromboembolic events after diagnosis and during therapy. These findings suggest, that use of anticoagulants was probably time restricted, as recommended for non-cancer patients, followed by switching back on antiplatelet agents. In previous studies, patients treated with oral anticoagulants plus cytoreduction had the lowest rate of recurrences (17.8\%) compared with those treated with cytoreduction $(50.0 \%)$, antiplatelet agents (35.2\%), or anticoagulation alone (44.1\%) (De Stefano et al. 2008). Follow-up studies reported similar results, with a lower incidence rate of recurrent venous thrombosis in patients receiving oral anticoagulants (4.7\% vs $8.9 \%$ ) (De Stefano et al. 2016). When investigating the duration of treatment these studies found that long-term treatment may reduce the incidence of thromboembolic complications (5.3\% versus $12.8 \%$ ). Potential benefit of a prolonged anticoagulant treatment was recently confirmed by independent groups (Wille et al. 2019) showing recurrent TECs in 36.1\% of PV patients who stopped anticoagulant therapy versus $8.6 \%$ of patients who continued anticoagulation. Physicians' recommendations for shortened duration of anticoagulant therapy may arise due to concerns regarding potential bleeding complications. However, in the studies cited above, treatment with anticoagulants did not significantly increase the incidence of major bleeding events, supporting long-term use of oral anticoagulants (OAC or DOAC) in PV patients who have a history of thrombotic events. This is supported by a high safety profile of direct oral anticoagulants (DOAC) in recent studies on MPN and cancer patients (Hamulyak et al. 2021; Huenerbein et al. 2021; Raskob et al. 2018).

In summary, this real life analysis of cytoreductive treatment in a cohort of high-risk PV patients underlines the importance of stringent initiation of pharmacologic cytoreduction according to current treatment guidelines and emphasizes the need for improved risk stratification.

Author contributions All authors contributed to the data collection. $\mathrm{CC}, \mathrm{RW}, \mathrm{FP}$ and FH contributed to the study conception and design. The first draft of the manuscript was written by FH and all authors commented on previous versions of the manuscript. All authors read and approved the final manuscript.

Funding Open Access funding enabled and organized by Projekt DEAL.

\section{Declarations}

Conflict of interest Study conception and data collection were supported by a grant (PVRetro2) from Novartis Inc. Regine Wunschel is employed by Novartis Inc. Florian Heidel has served as a consultant, speaker and advisory board member for Novartis, Celgene/BMS, CTI, $\mathrm{AOP}$ and Janssen and has received research funding from Novartis, Celgene/BMS and CTI.

Ethical standards No identifiable personal information was collected during the chart review, and the results of the chart review were reported as aggregated datasets of each center. Questionnaires and study materials were reviewed and approved by the institutional review board.

Open Access This article is licensed under a Creative Commons Attribution 4.0 International License, which permits use, sharing, adaptation, distribution and reproduction in any medium or format, as long as you give appropriate credit to the original author(s) and the source, provide a link to the Creative Commons licence, and indicate if changes were made. The images or other third party material in this article are included in the article's Creative Commons licence, unless indicated otherwise in a credit line to the material. If material is not included in the article's Creative Commons licence and your intended use is not permitted by statutory regulation or exceeds the permitted use, you will need to obtain permission directly from the copyright holder. To view a copy of this licence, visit http://creativecommons.org/licenses/by/4.0/.

\section{References}

Alvarez-Larran A, Pereira A, Cervantes F, Arellano-Rodrigo E, Hernandez-Boluda JC, Ferrer-Marin F, Angona A, Gomez M, Muina B, Guillen H et al (2012) Assessment and prognostic value of the European LeukemiaNet criteria for clinicohematologic response, resistance, and intolerance to hydroxyurea in polycythemia vera. Blood 119:1363-1369. https://doi.org/10.1182/ blood-2011-10-387787

Alvarez-Larran A, Kerguelen A, Hernandez-Boluda JC, Perez-Encinas M, Ferrer-Marin F, Barez A, Martinez-Lopez J, Cuevas B, Mata MI, Garcia-Gutierrez V et al (2016) Frequency and prognostic value of resistance/intolerance to hydroxycarbamide in 890 patients with polycythaemia vera. Br J Haematol 172:786-793. https://doi.org/10.1111/bjh.13886

Alvarez-Larran A, Perez-Encinas M, Ferrer-Marin F, HernandezBoluda JC, Ramirez MJ, Martinez-Lopez J, Magro E, Cruz Y, Mata MI, Aragues P et al (2017) Risk of thrombosis according to need of phlebotomies in patients with polycythemia vera treated with hydroxyurea. Haematologica 102:103-109. https://doi.org/ 10.3324/haematol.2016.152769

Arber DA, Orazi A, Hasserjian R, Thiele J, Borowitz MJ, Le Beau MM, Bloomfield CD, Cazzola M, Vardiman JW (2016) The 2016 revision to the World Health Organization classification of myeloid neoplasms and acute leukemia. Blood 127:2391-2405. https://doi.org/10.1182/blood-2016-03-643544

Barbui T, Barosi G, Birgegard G, Cervantes F, Finazzi G, Griesshammer M, Harrison C, Hasselbalch HC, Hehlmann R, Hoffman R et al (2011) Philadelphia-negative classical myeloproliferative neoplasms: critical concepts and management recommendations 
from European LeukemiaNet. J Clin Oncol 29:761-770. https:// doi.org/10.1200/JCO.2010.31.8436

Barbui T, Carobbio A, Rumi E, Finazzi G, Gisslinger H, Rodeghiero F, Randi ML, Rambaldi A, Gisslinger B, Pieri L et al (2014) In contemporary patients with polycythemia vera, rates of thrombosis and risk factors delineate a new clinical epidemiology. Blood 124:3021-3023. https://doi.org/10.1182/blood-2014-07-591610

Barbui T, Masciulli A, Marfisi MR, Tognoni G, Finazzi G, Rambaldi A, Vannucchi A (2015a) White blood cell counts and thrombosis in polycythemia vera: a subanalysis of the CYTO-PV study. Blood 126:560-561. https://doi.org/10.1182/blood-2015-04-638593

Barbui T, Thiele J, Vannucchi AM, Tefferi A (2015b) Rationale for revision and proposed changes of the WHO diagnostic criteria for polycythemia vera, essential thrombocythemia and primary myelofibrosis. Blood Cancer J 5:e337. https://doi.org/10.1038/ bcj. 2015.64

Barbui T, Vannucchi AM, Finazzi G, Finazzi MC, Masciulli A, Carobbio A, Ghirardi A, Tognoni G (2017) A reappraisal of the benefitrisk profile of hydroxyurea in polycythemia vera: a propensitymatched study. Am J Hematol 92:1131-1136. https://doi.org/10. 1002/ajh.24851

Barbui T, Tefferi A, Vannucchi AM, Passamonti F, Silver RT, Hoffman R, Verstovsek S, Mesa R, Kiladjian JJ, Hehlmann R et al (2018) Philadelphia chromosome-negative classical myeloproliferative neoplasms: revised management recommendations from European LeukemiaNet. Leukemia 32:1057-1069. https://doi.org/10.1038/ s41375-018-0077-1

Barosi G, Birgegard G, Finazzi G, Griesshammer M, Harrison C, Hasselbalch H, Kiladijan JJ, Lengfelder E, Mesa R, Mc Mullin MF et al (2010) A unified definition of clinical resistance and intolerance to hydroxycarbamide in polycythaemia vera and primary myelofibrosis: results of a European LeukemiaNet (ELN) consensus process. Br J Haematol 148:961-963. https://doi.org/10. 1111/j.1365-2141.2009.08019.x

Barosi G, Mesa R, Finazzi G, Harrison C, Kiladjian JJ, Lengfelder E, McMullin MF, Passamonti F, Vannucchi AM, Besses C et al (2013) Revised response criteria for polycythemia vera and essential thrombocythemia: an ELN and IWG-MRT consensus project. Blood 121:4778-4781. https://doi.org/10.1182/ blood-2013-01-478891

Benevolo G, Elli EM, Bartoletti D, Latagliata R, Tiribelli M, Heidel FH, Cavazzini F, Bonifacio M, Crugnola M, Binotto G et al (2021) Impact of comorbidities and body mass index on the outcome of polycythemia vera patients. Hematol Oncol. https://doi.org/10. 1002/hon.2843

Bonicelli G, Abdulkarim K, Mounier M, Johansson P, Rossi C, Jooste V, Andreasson B, Maynadie M, Girodon F (2013) Leucocytosis and thrombosis at diagnosis are associated with poor survival in polycythaemia vera: a population-based study of 327 patients. Br J Haematol 160:251-254. https://doi.org/10.1111/bjh.12117

Cerquozzi S, Barraco D, Lasho T, Finke C, Hanson CA, Ketterling RP, Pardanani A, Gangat N, Tefferi A (2017) Risk factors for arterial versus venous thrombosis in polycythemia vera: a single center experience in 587 patients. Blood Cancer J 7:662. https://doi.org/ 10.1038/s41408-017-0035-6

Chievitz E, Thiede T (1962) Complications and causes of death in polycythaemia vera. Acta Med Scand 172:513-523

Crodel CC, Jentsch-Ullrich K, Koschmieder S, Kämpfe D, Griesshammer M, Döhner K, Jost PJ, Wolleschak D, Isfort S, Stegelmann F, Jilg S (2020) Frequency of infections in 948 MPN patients: a prospective multicenter patient-reported pilot study. Leukemia 34(7):1949-1953

De Stefano V, Za T, Rossi E, Vannucchi AM, Ruggeri M, Elli E, Mico C, Tieghi A, Cacciola RR, Santoro C et al (2008) Recurrent thrombosis in patients with polycythemia vera and essential thrombocythemia: incidence, risk factors, and effect of treatments. Haematologica 93:372-380. https://doi.org/10.3324/haematol. 12053

De Stefano V, Za T, Rossi E, Vannucchi AM, Ruggeri M, Elli E, Mico C, Tieghi A, Cacciola RR, Santoro C et al (2010) Leukocytosis is a risk factor for recurrent arterial thrombosis in young patients with polycythemia vera and essential thrombocythemia. Am J Hematol 85:97-100. https://doi.org/10.1002/ajh.21593

De Stefano V, Ruggeri M, Cervantes F, Alvarez-Larran A, Iurlo A, Randi ML, Elli E, Finazzi MC, Finazzi G, Zetterberg E et al (2016) High rate of recurrent venous thromboembolism in patients with myeloproliferative neoplasms and effect of prophylaxis with vitamin K antagonists. Leukemia 30:2032-2038. https://doi.org/ 10.1038/leu.2016.85

De Stefano V, Carobbio A, Di Lazzaro V, Guglielmelli P, Iurlo A, Finazzi MC, Rumi E, Cervantes F, Elli EM, Randi ML et al (2018) Benefit-risk profile of cytoreductive drugs along with antiplatelet and antithrombotic therapy after transient ischemic attack or ischemic stroke in myeloproliferative neoplasms. Blood Cancer J 8:25. https://doi.org/10.1038/s41408-018-0048-9

Finazzi G, Barbui T (2008) Evidence and expertise in the management of polycythemia vera and essential thrombocythemia. Leukemia 22:1494-1502. https://doi.org/10.1038/leu.2008.177

Finazzi G, Caruso V, Marchioli R, Capnist G, Chisesi T, Finelli C, Gugliotta L, Landolfi R, Kutti J, Gisslinger H et al (2005) Acute leukemia in polycythemia vera: an analysis of 1638 patients enrolled in a prospective observational study. Blood 105:2664 2670. https://doi.org/10.1182/blood-2004-09-3426

Gangat N, Strand J, Li CY, Wu W, Pardanani A, Tefferi A (2007) Leucocytosis in polycythaemia vera predicts both inferior survival and leukaemic transformation. Br J Haematol 138:354-358. https:// doi.org/10.1111/j.1365-2141.2007.06674.x

Gisslinger H, Klade C, Georgiev P, Skotnicki A, Gercheva-Kyuchukova L, Egyed M, Rossiev V, Dulicek P, Illes A, Pylypenko H et al (2016) Final results from PROUD-PV a randomized controlled phase 3 trial comparing ropeginterferon Alfa- $2 b$ to hydroxyurea in polycythemia vera patients. Blood 128:475

Gisslinger H, Klade C, Georgiev P, Krochmalczyk D, Gercheva-Kyuchukova L, Egyed M, Rossiev V, Dulicek P, Illes A, Pylypenko $\mathrm{H}$ et al (2020) Ropeginterferon Alfa-2b: efficacy and safety in different age groups. Hemasphere 4:e485. https://doi.org/10.1097/ HS9.0000000000000485

Griesshammer M, Kiladjian JJ, Besses C (2019) Thromboembolic events in polycythemia vera. Ann Hematol 98:1071-1082. https:// doi.org/10.1007/s00277-019-03625-x

Griesshammer M, Wille K, Sadjadian P, Stegelmann F, Dohner K (2021) A review of hydroxyurea-related cutaneous adverse events. Expert Opin Drug Saf. https://doi.org/10.1080/14740338.2021. 1945032

Grunwald MR, Stein BL, Boccia RV, Oh ST, Paranagama D, Parasuraman S, Colucci P, Mesa R (2018) Clinical and disease characteristics from REVEAL at time of enrollment (baseline): prospective observational study of patients with polycythemia vera in the United States. Clin Lymphoma Myeloma Leuk 18:788. https:// doi.org/10.1016/j.clml.2018.08.009

Gruppo Italiano Studio Policitemia (1995) Polycythemia vera: the natural history of 1213 patients followed for 20 years. Ann Intern Med 123:656-664. https://doi.org/10.7326/0003-4819-123-9199511010-00003

Hamulyak EN, Daams JG, Leebeek FWG, Biemond BJ, Te Boekhorst PAW, Middeldorp S, Lauw MN (2021) A systematic review of antithrombotic treatment of venous thromboembolism in patients with myeloproliferative neoplasms. Blood Adv 5:113-121. https:// doi.org/10.1182/bloodadvances.2020003628 
Harrison CN, Koschmieder S, Foltz L, Guglielmelli P, Flindt T, Koehler M, Mathias J, Komatsu N, Boothroyd RN, Spierer A et al (2017) The impact of myeloproliferative neoplasms (MPNs) on patient quality of life and productivity: results from the international MPN Landmark survey. Ann Hematol 96:1653-1665. https://doi.org/10.1007/s00277-017-3082-y

Heidel FH, Al-Ali HK, Hirt C, Kampfe D, Jentsch-Ullrich K, Junghanss C, Nowak R, Schwarzer A, Spohn C, Vucinic V et al (2018) Questions arising on phlebotomy in polycythemia vera: prophylactic measures to reduce thromboembolic events require patient-focused decisions. Leukemia 32:2085-2087. https://doi. org/10.1038/s41375-018-0214-X

Huenerbein K, Sadjadian P, Becker T, Kolatzki V, Deventer E, Engelhardt C, Griesshammer M, Wille K (2021) Direct oral anticoagulants (DOAC) for prevention of recurrent arterial or venous thromboembolic events (ATE/VTE) in myeloproliferative neoplasms. Ann Hematol 100:2015-2022. https://doi.org/10.1007/ s00277-020-04350-6

Hultcrantz M, Bjorkholm M, Dickman PW, Landgren O, Derolf AR, Kristinsson SY, Andersson TML (2018) Risk for arterial and venous thrombosis in patients with myeloproliferative neoplasms: a population-based cohort study. Ann Intern Med 168:317-325. https://doi.org/10.7326/M17-0028

Jentsch-Ullrich K, Eberhardt J, Zeremski V, Koehler M, Wolleschak D, Heidel FH (2016) Characteristics and treatment of polycythemia vera patients in clinical practice: a multicenter chart review on 1476 individuals in Germany. J Cancer Res Clin Oncol 142:20412049. https://doi.org/10.1007/s00432-016-2209-1

Kiladjian JJ, Cassinat B, Turlure P, Cambier N, Roussel M, Bellucci S, Menot ML, Massonnet G, Dutel JL, Ghomari K et al (2006) High molecular response rate of polycythemia vera patients treated with pegylated interferon alpha-2a. Blood 108:2037-2040. https://doi. org/10.1182/blood-2006-03-009860

Kiladjian JJ, Cassinat B, Chevret S, Turlure P, Cambier N, Roussel M, Bellucci S, Grandchamp B, Chomienne C, Fenaux P (2008) Pegylated interferon-alfa-2a induces complete hematologic and molecular responses with low toxicity in polycythemia vera. Blood 112:3065-3072. https://doi.org/10.1182/blood-2008-03-143537

Landolfi R, Marchioli R, Kutti J, Gisslinger H, Tognoni G, Patrono C, Barbui T, European Collaboration on Low-Dose Aspirin in Polycythemia Vera (2004) Efficacy and safety of low-dose aspirin in polycythemia vera. N Engl J Med 350:114-124. https://doi.org/ 10.1056/NEJMoa035572

Landtblom AR, Andersson TML, Dickman PW, Smedby KE, Eloranta S, Batyrbekova N, Samuelsson J, Bjorkholm M, Hultcrantz M (2020) Risk of infections in patients with myeloproliferative neoplasms a population-based cohort study of 8363 patients. Leukemia 35:476

Lengfelder E, Baerlocher GM, Gisslinger HMG, Petrides PE (2014) Polycythaemia Vera (PV). Onkopedia-Leitlinie der Deutschen Gesellschaft für Hämatologie und Onkologie (DGHO). https:// www.onkopedia.com/de/onkopedia/guidelines/polycythaemiavera-pv/@ @ guideline/html/index.html

Lengfelder E, Baerlocher GM, Döhner K, Gisslinger H, Grießhammer M, Petrides PE (2018) Polycythaemia vera (PV). OnkopediaLeitlinien der DGHO. https://www.onkopedia.com/de/onkopedia/ guidelines/polycythaemia-vera-pv/@ @ guideline/html/index.html

Lim Y, Lee JO, Kim SH, Kim JW, Kim YJ, Lee KW, Lee JS, Bang SM (2015) Prediction of thrombotic and hemorrhagic events during polycythemia vera or essential thrombocythemia based on leukocyte burden. Thromb Res 135:846-851. https://doi.org/10.1016/j. thromres.2015.02.023

Marchioli R, Finazzi G, Specchia G, Cacciola R, Cavazzina R, Cilloni D, De Stefano V, Elli E, Iurlo A, Latagliata R et al (2013) Cardiovascular events and intensity of treatment in polycythemia vera. $\mathrm{N}$ Engl J Med 368:22-33. https://doi.org/10.1056/NEJMoa1208500
McMullin MF, Harrison CN, Ali S, Cargo C, Chen F, Ewing J, Garg M, Godfrey A et al (2019) A guideline for the diagnosis and management of polycythaemia vera. A British society for haematology guideline. Br J Haematol 184:176-191. https://doi.org/10.1111/ bjh. 15648

Mesa R, Miller CB, Thyne M, Mangan J, Goldberger S, Fazal S, Ma X, Wilson W, Paranagama DC, Dubinski DG et al (2016) Myeloproliferative neoplasms (MPNs) have a significant impact on patients' overall health and productivity: the MPN Landmark survey. BMC Cancer 16:167. https://doi.org/10.1186/s12885-016-2208-2

Mesa RA, Miller CB, Thyne M, Mangan J, Goldberger S, Fazal S, Ma X, Wilson W, Paranagama DC, Dubinski DG et al (2017) Differences in treatment goals and perception of symptom burden between patients with myeloproliferative neoplasms (MPNs) and hematologists/oncologists in the United States: findings from the MPN Landmark survey. Cancer 123:449-458. https://doi.org/10. 1002/cncr.30325

Palandri F, Breccia M, Bonifacio M, Polverelli N, Elli EM, Benevolo G, Tiribelli M, Abruzzese E, Iurlo A, Heidel FH et al (2020) Life after ruxolitinib: Reasons for discontinuation, impact of disease phase, and outcomes in 218 patients with myelofibrosis. Cancer 126:1243-1252. https://doi.org/10.1002/cncr.32664

Parasuraman S, DiBonaventura M, Reith K, Naim A, Concialdi K, Sarlis NJ (2015) Patterns of hydroxyurea use and clinical outcomes among patients with polycythemia vera in real-world clinical practice: a chart review. Exp Hematol Oncol 5:3. https://doi.org/10. 1186/s40164-016-0031-8

Perner F, Perner C, Ernst T, Heidel FH (2019) Roles of JAK2 in aging, inflammation hematopoiesis and malignant transformation. Cells. https://doi.org/10.3390/cells8080854

Polverelli N, Catani L, Vianelli N, Baccarani M, Cavo M, Palandri F (2015) Ruxolitinib- but not fedratinib-induced extreme thrombocytosis: the combination therapy with hydroxyurea and ruxolitinib is effective in reducing platelet count and splenomegaly/constitutional symptoms. Ann Hematol 94:1585-1587. https://doi.org/ 10.1007/s00277-015-2397-9

Raskob GE, van Es N, Verhamme P, Carrier M, Di Nisio M, Garcia D, Grosso MA, Kakkar AK, Kovacs MJ, Mercuri MF et al (2018) Edoxaban for the treatment of cancer-associated venous thromboembolism. N Engl J Med 378:615-624. https://doi.org/10.1056/ NEJMoa1711948

Stegelmann F, Wille K, Busen H, Fuchs C, Schauer S, Sadjadian P, Becker T, Kolatzki V, Dohner H, Stadler R et al (2021) Significant association of cutaneous adverse events with hydroxyurea: results from a prospective non-interventional study in BCR-ABL1-negative myeloproliferative neoplasms (MPN) - on behalf of the German Study Group-MPN. Leukemia 35:628-631. https://doi.org/ 10.1038/s41375-020-0945-3

Tefferi A (2013) Polycythemia vera and essential thrombocythemia: 2013 update on diagnosis, risk-stratification, and management. Am J Hematol 88:507-516. https://doi.org/10.1002/ajh.23417

Tefferi A, Rumi E, Finazzi G, Gisslinger H, Vannucchi AM, Rodeghiero F, Randi ML, Vaidya R, Cazzola M, Rambaldi A et al (2013) Survival and prognosis among 1545 patients with contemporary polycythemia vera: an international study. Leukemia 27:18741881. https://doi.org/10.1038/leu.2013.163

Vannucchi AM, Barbui T, Cervantes F, Harrison C, Kiladjian JJ, Kroger N, Thiele J, Buske C, Committee EG (2015a) Philadelphia chromosome-negative chronic myeloproliferative neoplasms: ESMO Clinical Practice Guidelines for diagnosis, treatment and follow-up. Ann Oncol 26(Suppl 5):v85-99. https://doi.org/10. 1093/annonc/mdv203

Vannucchi AM, Kiladjian JJ, Griesshammer M, Masszi T, Durrant S, Passamonti F, Harrison CN, Pane F, Zachee P, Mesa R et al (2015b) Ruxolitinib versus standard therapy for the treatment of 
polycythemia vera. N Engl J Med 372:426-435. https://doi.org/ 10.1056/NEJMoa1409002

Verstovsek S, De Stefano V, Heidel FH, Zuurman M, Zaiac M, Bigan E, Ruhl M, Meier C, Beffy M, Kiladjian JJ (2019) US optum database study in polycythemia vera patients: thromboembolic events (TEs) with hydroxyurea (HU) Vs ruxolitinib switch therapy and machine-learning model to predict incidence of TES and HU failure. Blood 134:1659

Wille K, Sadjadian P, Becker T, Kolatzki V, Horstmann A, Fuchs C, Griesshammer M (2019) High risk of recurrent venous thromboembolism in BCR-ABL-negative myeloproliferative neoplasms after termination of anticoagulation. Ann Hematol 98:93-100. https://doi.org/10.1007/s00277-018-3483-6

Publisher's Note Springer Nature remains neutral with regard to jurisdictional claims in published maps and institutional affiliations.

\section{Authors and Affiliations}

\section{Carl C. Crodel ${ }^{1} \cdot$ Kathleen Jentsch-Ullrich ${ }^{2} \cdot$ Marcel Reiser $^{3} \cdot$ Lutz Jacobasch $^{4} \cdot$ Annette Sauer $^{5} \cdot$ Hans Tesch $^{6}$. Thomas Ulshöfer ${ }^{7} \cdot$ Regine Wunschel $^{8} \cdot$ Francesca Palandri $^{9} \cdot$ Florian H. Heidel $^{1,10}$ (])}

1 Innere Medizin 2, Hämatologie und Onkologie, Universitätsklinikum Jena, Jena, Germany

2 Gemeinschaftspraxis Hämatologie/Onkologie, Magdeburg, Germany

3 Pioh Köln Zentrum, Cologne, Germany

4 Gemeinschaftspraxis Hämatologie und Onkologie, Dresden, Germany

5 MVZ für Blut—und Krebserkrankungen, Potsdam, Germany

6 Centrum für Hämatologie und Onkologie, Frankfurt, Germany

7 Cor/On/Med, Ludwigsburg, Germany
8 Novartis Pharma GmbH, Nürnberg, Germany

9 Department of Experimental, Diagnostic and Specialty Medicine, Institute of Hematology L. and A. Seràgnoli, S. Orsola-Malpighi Hospital, University of Bologna, Bologna, Italy

10 Innere Medizin C, Hämatologie und Onkologie, Universitätsmedizin Greifswald, Sauerbruchstrasse, 17475 Greifswald, Germany 